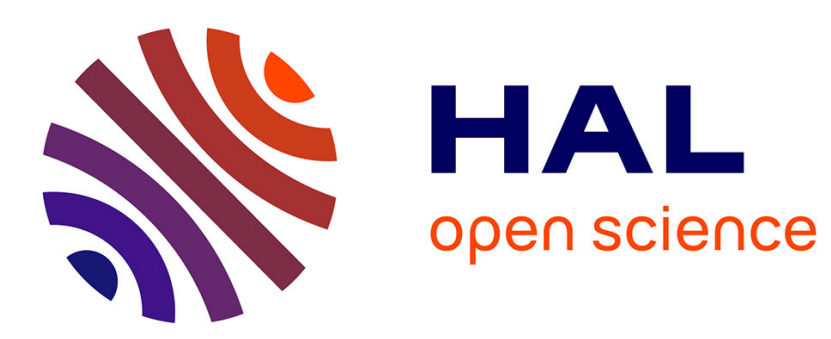

\title{
Scaling laws in aeolian sand transport: Erodible versus non-erodible bed
}

Alexandre Valance, Tuan Duc Ho, Ahmed Ould El Moctar, Pascal Dupont

\section{To cite this version:}

Alexandre Valance, Tuan Duc Ho, Ahmed Ould El Moctar, Pascal Dupont. Scaling laws in aeolian sand transport: Erodible versus non-erodible bed. POWDERS AND GRAINS 2013, Jul 2013, Sydney, Australia. pp.1059-1062, 10.1063/1.4812117 . hal-00843054

\section{HAL Id: hal-00843054 https://hal-univ-rennes1.archives-ouvertes.fr/hal-00843054}

Submitted on 10 Jul 2013

HAL is a multi-disciplinary open access archive for the deposit and dissemination of scientific research documents, whether they are published or not. The documents may come from teaching and research institutions in France or abroad, or from public or private research centers.
L'archive ouverte pluridisciplinaire HAL, est destinée au dépôt et à la diffusion de documents scientifiques de niveau recherche, publiés ou non, émanant des établissements d'enseignement et de recherche français ou étrangers, des laboratoires publics ou privés. 


\title{
Scaling laws in aeolian sand transport: Erodible versus Non-erodible bed
}

\author{
A. Valance*, T. D. Ho*, A. Ould El Moctar ${ }^{\dagger}$ and P. Dupont** \\ * Institut de Physique de Rennes, UMR UR1-CNRS 6251, Université de Rennes 1, 35042 Rennes cedex, France \\ ${ }^{\dagger}$ Laboratoire de Thermocinétique, Polytech. Nantes, CNRS UMR 6607, 44306 Nantes, France \\ ** LGCGM, INSA de Rennes, Campus Beaulieu, 35043 Rennes, France
}

\begin{abstract}
We investigated via wind-tunnel experiments the role of the boundary conditions at the bed in the aeolian sand transport. We analyzed two different bed configurations: one with a sandy erodible bed and the other with a non-erodible bed. By using Particle Tracking Velocimetry technique (PTV), we characterized the saltation layer in both configurations and evidenced constrating features. We show in particular that over an erodible bed the particle velocity in the saltation layer and the saltation length are almost invariant with the wind strength, whereas over a non-erodible bed these quantities vary significantly with the air friction speed. It results that the particle transport rate over an erodible bed does not exhibit a cubic dependence with the air friction speed, as predicted by Bagnold, but a quadratic one. This contrasts with saltation over nonerodible bed where the cubic Bagnold scaling holds. Our findings emphasize the crucial role of the boundary conditions at the bed and may have important practical consequences for aeolian sand transport in natural environment.
\end{abstract}

Keywords: Aeolian sand transport, wind tunnel experiment, saltation

PACS: $47.55 . \mathrm{Kf}, 45.70 . \mathrm{Mg}, 92.40 . \mathrm{Gc}$

\section{INTRODUCTION}

The study of wind-blown sand started seventy years ago with the seminal work of Bagnold [1]. He was the first to identify the dominant mode of sand transport, termed saltation, which consists of grains traveling in a sequence of ballistic trajectories and producing a splash of new ejected grains when colliding back onto the soil. Numerous theoretical, numerical and experimental approaches were developed since to improve our understanding of aeolian sand transport. Major progress were achieved recently $[2,3,4,5,6,7]$ through wind tunnel experiments thanks to the development of fast video cameras and imaging techniques.

We present here experimental results obtained in wind-tunnel that emphasize the crucial role of the boundary conditions at the bed in the aeolian sand transport. We investigate the saltation transport in two different bed configurations: one with a sand erodible and the other with a rigid and bumpy bed.

\section{EXPERIMENTAL FACILITIES}

The experiments reported here were performed in a $6 \mathrm{~m}$ long wind tunnel with a cross-section of dimensions $0.27 m \times 0.27 m$ [6]. The nominal air velocity $U_{\infty}$ (i.e., outside from the boundary layer) in the wind tunnel can be varied between 0 and $20 \mathrm{~m} / \mathrm{s}$. According to the configuration used, the floor of the tunnel is covered either by a sand bed of uniform height or by a rigid and bumpy substrate (which is achieved by gluing a monolayer of sand on a flat base). At the upwind end of the tunnel, a sand supply system allows a constant incoming mass transport rate $q_{i n}$, while at the downwind end sand is collected using a trap.We used sand with a median diameter $d=230 \mu \mathrm{m}$ and a density $\rho_{p}=2470 \mathrm{~kg} / \mathrm{m}^{3}$.

In both bed configurations, the wind tunnel was fed with sand grains at constant incoming rate $q_{\text {in }}$ (ranging from 0 to $24 \mathrm{~g} / \mathrm{s}$ ). Each run lasted several minutes during which we measured the particle velocity throughout the saltation layer via Particle Tracking Techniques [5]. After each run, the sand collected at the exit of the tunnel was weighed and the outgoing transport rate $q_{\text {out }}$ estimated.

\section{SAND TRANSPORT CAPACITY}

In the case of a rigid bed the incoming and outgoing transport rates are identical as soon as no sand is deposited within the tunnel. Thus, given the incoming transport rate, there exists a critical nominal velocity below which the air flow is not able to sustain the imposed transport rate and deposition occurs. In other words, for a given wind strength, the transport capacity of the flow is limited.The maximum transport capacity increases with increasing air friction speed $u_{*}$ as shown in Fig. 1 and can be well approximated by $q_{\max } \propto\left(u^{*}-u_{c r}^{*}\right)\left(u^{* 2}-u_{c r}^{* 2}\right)$ with $u_{c r}^{*} \approx 0.15 \mathrm{~m} / \mathrm{s}$. An other fit of the form $u^{*}\left(u^{* 2}-\right.$ $\left.u_{c r}^{* 2}\right)$ would work as well but at this stage is not possible to discriminate between the two due to the lack of data 
for air friction speed close to $u_{c r}^{*}$.

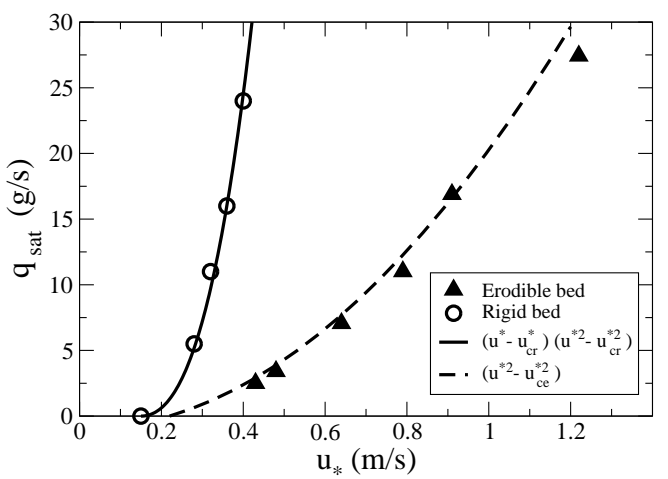

FIGURE 1. Maximum capacity of transport vs the friction velocity over rigid and erodible bed.

The situation is drastically different in the erodible bed configuration where the transport is controlled by the erosion/deposition balance. In this case, the outgoing transport rate (measured at the exit of the tunnel) depends solely on the wind strength and is independent of the incoming transport rate. The outgoing transport rate corresponds to the saturated sand flux $q_{\text {sat }}$ defined as the maximum transport rate that a flow (of given strength) in interaction with an erodible bed can transport. As a consequence, if the incoming transport rate is greater (resp. smaller) than $q_{\text {sat }}$, there is a net deposition (resp. a net erosion) of sand. Most importantly, the saturated transport rate is found to scale quadractically with the air friction speed unlike cubic Bagnold scaling [1]: $q_{s a t} \propto\left(u^{* 2}-u_{c e}^{* 2}\right)$ with $u_{c e}^{*}=0.20 \mathrm{~m} / \mathrm{s}$ (see Fig. 1). This scaling contrasts with that obtained in the non-erodible configuration.

These differences in the scaling transport laws can be understood through of a detailed characterization the particle motion in the saltation layer as presented below.

\section{PARTICLE VELOCITY PROFILE}

Particle velocity over a rigid bed is found to vary linearly with height (see Fig. 2). The shear rate is relatively small in comparison with the erodible bed configuration $\left(20 s^{-1}\right.$ against $\left.60 s^{-1}\right)$. The most salient feature is the existence of a large non-zero slip velocity $u_{0}$ which increases linearly with increasing friction velocity but is independent of the incoming transport rate $q_{i n}$.In other words, the particle velocity over a rigid bed is only dependent on the wind strength.

It is worth noting that $u_{0}$ represents the average horizontal particle velocity at the bed including the ascending and descending saltating particles [i.e., $u_{0}=$ $\left.\left(u_{0 \uparrow}+u_{0 \downarrow}\right) / 2\right]$. The horizontal particle velocity difference, $u_{0 \downarrow}-u_{0 \uparrow}$, as well as the ascending vertical velocity $v_{0 \uparrow}$, are also linear functions of the air friction velocity: $\left(u_{0 \downarrow}-u_{0 \uparrow}\right) \approx 10.0\left(u^{*}-u_{c r}^{*}\right)$ and $v_{0 \uparrow} \approx 5.8\left(u^{*}-u_{c r}^{*}\right)$.

These results contrast with the erodible bed configuration where the slip velocity $u_{0}$ and the ascending vertical velocity $v_{0 \uparrow}$ are small and independent of the friction velocity $\left(u_{0} \approx 1.1 \mathrm{~m} / \mathrm{s}\right.$ and $\left.v_{0 \uparrow} \approx 0.5 \mathrm{~m} / \mathrm{s}\right)$.

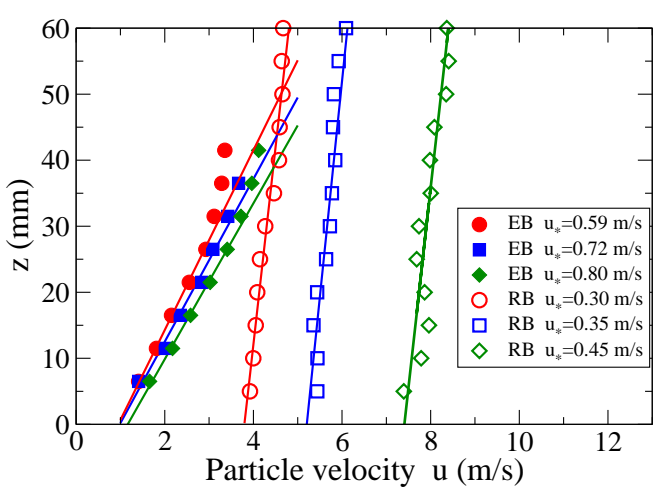

FIGURE 2. Mean horizontal particle velocity profiles over rigid bed (open symbols) for various friction velocity at a given incoming transport rate $q_{i n}=11 \mathrm{~g} / \mathrm{s}$ and over erodible (filled symbols).

Taking advantage of these features, it is possible to estimate the mean saltation length. Indeed, neglecting vertical drag on the particles, the mean flight time of saltating particles $T_{\text {salt }}$ can be expressed as $T_{\text {salt }} \approx$ $2 v_{0 \uparrow} / g$ and considering that saltating particles undergo a constant horizontal acceleration $\left(u_{0 \downarrow}-u_{0 \uparrow}\right) / T_{\text {salt }}$ during their flight, the mean saltation length is given by $l_{\text {salt }} \approx\left(u_{0 \uparrow}+u_{0 \downarrow}\right) v_{0 \uparrow} / g$. The mean saltation length over a rigid bed is found to scale quadratically with the friction speed: $l_{\text {salt }} \approx 2.5\left(u^{*}-u_{c r}^{*}\right)^{2} / g$. In contrast, the latter is invariant over an erodible bed.

\section{PARTICLE VELOCITY DISTRIBUTION}

Fig. 3 shows the vertical velocity distribution of the saltating particles close to the ground (i.e., at $z \approx 10 d$ above the bed surface within a layer $d z \approx 5 d$ ) in the case of an erodible bed. Three important features should be emphasized. First, these distributions exhibit unambiguously a deviation from a Gaussian distribution. A longtail statistic is clearly observed. Second, they do not significantly change with the shear velocity confirming that the features of the saltating particles are invariant with the wind strength. Third, they are almost symmetrical with respect to the origin indicating that saltating particles experience a negligible drag in the vertical direction during their flight. In other terms, upward and downward velocities have similar features.

Actually, the vertical velocity distribution can be well approximated by a lognormal type distribution of the 


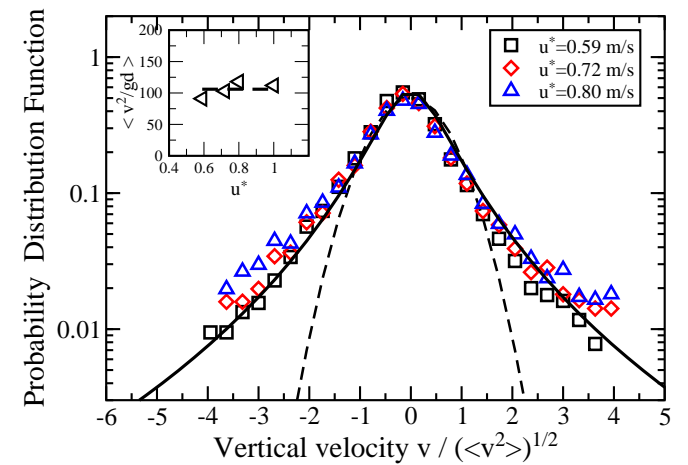

FIGURE 3. Vertical velocity distribution $p(v)$ of saltating particles located close to the ground (at $z=10 d$ within a layer $d z=5 d$ ) for various wind strengths measured in terms of the Shields parameter $S$. The dash and solid lines correspond to the best fits obtained respectively with a normal law $(m=0$, $s=7.0)$ and a log-normal type law $(\mu=1.6, \sigma=1.0)$. Inset: Variation of $\left\langle v^{2} / g d\right\rangle$ with the shear velocity $u^{*}$.

following form:

$$
P(v / \sqrt{g d})=A \frac{e^{-\left[\ln \sqrt{\left(v^{2}+2 g z\right) / g d}-\mu\right]^{2} /\left(2 \sigma^{2}\right)}}{\sqrt{\left(v^{2}+2 g z\right) / g d}},
$$

where $A$ is a constant of normalization and $\mu$ and $\sigma$ are free parameters of the distribution. $z$ is the altitude where particle vertical velocities were measured and $\sqrt{v^{2}+2 g z}$ corresponds to the particle velocity extrapolated at the bed. This distribution is nothing but a truncated lognormal distribution. It is important to note that due to technical limitation of the particle tracking technique, it is not possible to get accurate measurements at height below $z=10 d$. As a consequence, we miss the low energetic grains of the velocity distribution.

Vertical velocity distributions obtained over a rigid bed exhibit contrasting features (see Fig. 4). First, the symmetry between upward and downward velocities is broken. This is a manifestation of air drag effect which is no longer negligible because saltating particles over rigid bed experience much higher jump than over an erodible bed [6]. Second, the right part of the distribution corresponding to upward velocities is extremely well described by a Gaussian law, thus contrasting with the lognormal distribution obtained over erodible bed. Third, the distributions over rigid bed are much wider than those over erodible bed and their width increases with increasing wind strength (see Inset of Fig. 4). Typically, $\left\langle v_{u p}^{2} / g d\right\rangle$ varies from 300 to 1500 for shear velocity ranging from 0.2 to $0.4 \mathrm{~m} / \mathrm{s}$. Conversely, for transport over an erodible bed, the velocity variance is on the order of 100 and is invariant with the wind strength.

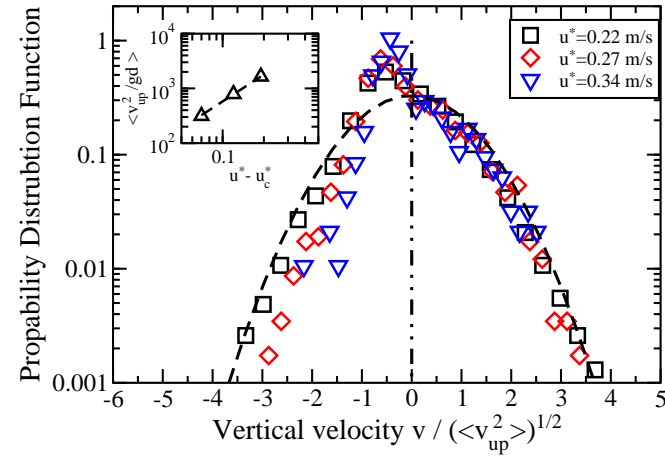

FIGURE 4. Distribution of the vertical particle velocity close to the ground (i.e., $z \approx 10 d$ ) obtained over a rigid bed for various wind shear velocity $q_{\text {in }}=5.5 \mathrm{~g} / \mathrm{s}$. Solid line represents a Gaussian distribution that best fits the upward velocities. Inset: Variation of $\left\langle v_{u p}^{2} / g d\right\rangle$ with the shear velocity.

\section{CONCENTRATION PROFILE}

We found that the vertical particle volume fraction over a rigid bed decreases with height at an exponential rate $v(z)=v_{0} \exp \left(-z / l_{v}\right)$ (see Fig. 5). At a given incoming

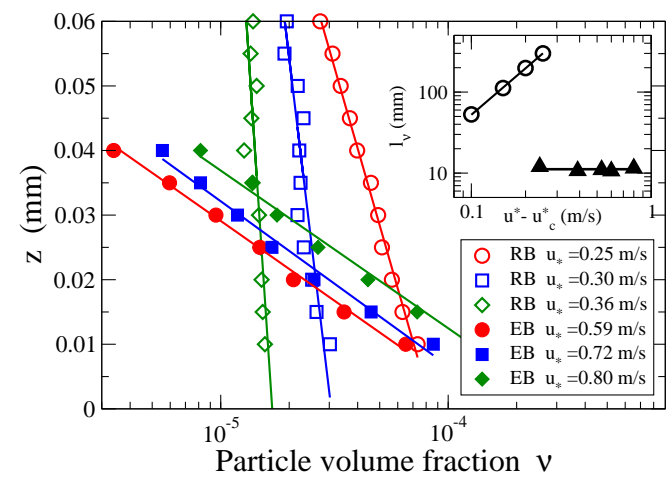

FIGURE 5. Concentration profiles versus height over rigid bed at given incoming transport rate $q_{\text {in }}=11 \mathrm{~g} / \mathrm{s}$ (open symbols) and over erodible bed (filled symbols) for different wind strengths. Inset: Corresponding characteristic decay length versus the friction velocity over a rigid bed (open symbols) and an erodible bed (filled symbols).

transport rate, particle concentration decreases with increasing friction velocity by virtue of mass conservation. Besides, the characteristic decay length $l_{v}$, which can be seen as an estimation of the height of the saltating layer, varies significantly with the friction velocity (see Inset Fig. 5): $l_{v} \approx 0.48\left(u^{*}-u_{c r}^{*}\right)^{2} / g$. This result is completely correlated with the increase of the variance of the vertical velocity distribution (see Inset of Fig. 4).

This contrasts again with the erodible bed configuration where the decay length is invariant. These results are reminiscent of those obtained for the mean saltation length. Finally, it is worth emphasizing that the decay length over rigid bed is much greater than that over erodi- 
ble bed (from 50 to $300 \mathrm{~mm}$ against $11 \mathrm{~mm}$ ). In other words, the saltation layer over a rigid bed is much thicker than over an erodible bed. A direct consequence of this is that the particle concentration averaged across the saltation layer is much smaller over a rigid bed than over an erodible bed. This provides an explanation for the fact that the air friction velocity over a rigid bed is not significantly altered by the presence of particles in the flow.

\section{INTERPRETATION AND DISCUSSION}

Scaling laws - In saltation transport over an erodible bed, as saltation starts, the number of saltating grains first increases exponentially due to multiplicative process of the splash events [8]. Wind loses momentum to accelerate the grains and the flux eventually saturates after a certain distance. At saturation, the air borne shear stress at the bed decreases to the critical shear stress $\tau_{c}$ [9], and the corresponding transport rate, $q_{s a t}$, can be expressed by virtue of momentum conservation as:

$$
q_{s a t}=\frac{l_{\text {salt }}}{u_{0 \downarrow}-u_{0 \uparrow}}\left(\rho u^{* 2}-\rho u_{c}^{* 2}\right) .
$$

where $l_{\text {salt }}$ is the mean saltation length and $u_{0 \downarrow}$ (resp. $u_{0 \uparrow}$ ) is the mean horizontal velocity of saltating grains before they collide the bed (resp. when they leave the bed).

We have seen that for transport over an erodible bed the mean saltation length as well as the horizontal particle velocity difference at the bed $u_{0 \downarrow}-u_{0 \uparrow}$ are independent of the wind strength. These features are explained by the strong coupling between the air flow and the sand particles in the saltation layer resulting from the fact that the saltating cloud is confined within a thin layer of few tens of millimeters. An increase of the wind strength essentially leads to an augmentation the particle concentration but leaves the particle speed almost unchanged. Using Eq. 2, it then results that the sand transport rate over an erodible bed scales as $\left(u^{* 2}-u_{c}^{* 2}\right)$.

The situation is drastically different over a rigid bed. The mean saltation length and the particle velocity at the bed increase with increasing wind strength respectively as $\left(u^{*}-u_{c}^{*}\right)^{2}$ and $\left(u^{*}-u_{c}^{*}\right)$, providing a cubic dependence for the maximum capacity of transport: $q_{\max } \propto$ $\left(u^{*}-u_{c}^{*}\right)\left(u^{* 2}-u_{c}^{* 2}\right)$. This last outcome relies on the weak coupling between the saltating grain and the air flow, resulting from the large vertical extension of the saltating layer.

Velocity distribution - The results on the particle velocity distribution indicate that there is a marked difference between the rigid and erodible case. While the liftoff velocities of grains saltating over a rigid bed obey a Gaussian distribution, those saltating over an erodible bed exhibit a long tail statistic that can be well described by a lognormal type law. The deviation from a Gaussian law can be therefore attributed to the splash process which is solely present in the case of transport over an erodible bed. The identification of the intimate physical grounds is not a trivial issue. A possible explanation may be found in the fundamental characteristics of the Splash process. The long tail statistics of the lift-off velocity distributions of saltating grains is reminiscent of the velocity distribution of the grains ejected from a single splash event. Recent model experiments on the splash collision process $[10,7]$ have indeed shown that the resulting velocity distribution of the splashed grains obeys a lognormal law. This leads us to conjecture that the latter is intimately connected with the lift-off velocity distribution in a steady and fully developed saltation state.

\section{CONCLUSION}

We showed that the aeolian transport over a rigid bed differs drastically from that over an erodible bed. Over an erodible bed, the particle velocity in the saltation layer and the salatation length are almost invariant with the friction velocity, whereas over a non-erodible bed these quantities vary significantly with the wind strength. It results that the particle transport rate over an erodible bed does not exhibit a cubic dependence with the air friction speed, as predicted by Bagnold, but a quadratic one. This contrasts with saltation over non-erodible bed where the cubic Bagnold scaling holds. Our findings emphasize the crucial role of the boundary conditions at the bed and may have important practical consequences for aeolian sand transport in natural environment.

\section{REFERENCES}

1. R. A. Bagnold, The Physics of blown sand and desert dunes, Chapman and Hall, Methuen, London, 1941.

2. P. Napalnis, J. C. R. Hunt, and C. F. Barrett, J. Fluid Mech. 251, 661-685 (1993).

3. Z. Dong, X. Liu, F. Li, H. Wang, and A. Zhao, Earth Surface Processes and Landforms 29, 343-358 (2004).

4. H. Cheng, X. Zou, and C. Zhang, Journal of Geophysical Research-Atmospheres 111, D22205 (2006).

5. M. Creyssels, P. Dupont, A. O. E. Moctar, A. Valance, I. Cantat, J. Pasini, J. Jenkins, and K. Rasmussen, Journal of Fluid Mechanics 625, 47-74 (2009).

6. T. Ho, A. Valance, P. Dupont, and A. O. E. Moctar, Phys. Rev. Lett. 106, 094501 (2011).

7. T. Ho, A. Valance, P. Dupont, and A. O. E. Moctar, Phys. Rev. E 85, 052301 (2012).

8. R. S. Anderson, and P. K. Haff, Science 241, 820-823 (1988).

9. P. R. Owen, J. Fluid Mech. 20, 225-242 (1964).

10. D. Beladjine, M. Ammi, L. Oger, A. Valance, and D. Bideau, Phys. Rev. E 75, 61305-61317 (2007). 